\title{
INDÚSTRIA CULTURAL, EDUCAÇÃO E TRABALHO DOCENTE: DA SEMIFORMAÇÃO À EMANCIPAÇÃO HUMANA
}

\author{
INDUSTRIA CULTURAL, EDUCACIÓN Y LABOR DOCENTE: DE LA SEMI-FORMACIÓN \\ A LA EMANCIPACIÓN HUMANA
}

\section{CULTURAL INDUSTRY, EDUCATION AND TEACHER WORK: FROM SEMI-FORMATION TO HUMAN EMANCIPATION}

\author{
Marta Regina Furlan de OLIVEIRA ${ }^{1}$ \\ Anilde Tombolato Tavares da SILVA ${ }^{2}$ \\ Cândida Alayde de Carvalho BITTENCOURT ${ }^{3}$ \\ Zuleika Aparecida Claro PIASSA ${ }^{4}$
}

Ao mergulhar numa discussão importante, espera-se que dela se possa sair com uma amplitude maior de saberes, com a compreensão refinada da temática desenvolvida, e com a proposição de novos conhecimentos, seja para a dinâmica existencial, para a emancipação profissional ou para a convivência social.

Foi esta a experiência realizada ao elaborarmos essa proposta de Dossiê, intitulada: "Indústria Cultural, Educação e Trabalho Docente: da semiformação à emancipação humana", organizada à luz dos estudos, discussões e pesquisas que vêm sendo desenvolvidas nos últimos 10 (dez) anos pelo Grupo de Estudos e Pesquisa em Educação, Infância e Teoria Crítica da Universidade Estadual de Londrina (GEPEITC/UEL) e que, de certa forma, estão em sintonia com os fundamentos da Teoria Crítica de Sociedade ${ }^{5}$.

No trajeto desse estudo tivemos a oportunidade de conhecer grupos, estudiosos da área, pesquisadores renomados do Brasil e de Países Ibero-Americanos que vêm há mais de 20 (vinte)

${ }^{1}$ Universidade Estadual de Londrina (UEL), Londrina - PR - Brasil. Docente do programa de pós-graduação em Educação. Pós-doutora em Educação. ORCID: http://orcid.org/0000-0003-2146-2557. Lattes: http://lattes.cnpq.br/ 8423465824507075. E-mail: marta.furlan@yahoo.com.br

${ }^{2}$ Universidade Estadual de Londrina (UEL), Londrina - PR - Brasil. Docente do Departamento de Educação. Pósdoutorado em $\quad$ Educação. $\quad$ ORCID: https://orcid.org/0000-0001-8391-880X. Lattes: http://lattes.cnpq.br/3570231779830818.E-mail: anildetombolato@gmail.com

${ }^{3}$ Universidade Estadual de Londrina (UEL), Londrina - PR - Brasil. Docente da área de formação de professores de Arte. Pós-doutorado em Educação. ORCID: https://orcid.org/0000-0001-9299-146X. Lattes: http://lattes.cnpq.br/8604831792425650.E-mail: candida.carvalho@uel.br

4 Universidade Estadual de Londrina (UEL), Londrina - PR - Brasil. Docente do departamento de educação. Doutoranda em Educação. ORCID: https://orcid.org/0000-0001-7080-0255. Lattes: http://lattes.cnpq.br/8460152764659926. E-mail: zupiassa@gmail.com

5 A Teoria Crítica de Sociedade é o conjunto de reflexões de um grupo de intelectuais marxistas, não ortodoxos, alemães, que a partir dos anos 1920 desenvolveram pesquisas e se posicionaram como pensadores sobre problemas filosóficos, estéticos, sociais, culturais, educacionais gerados pelo sistema capitalista de sua época (WIGGERHAUS, 2002, p. 33-40). 
anos desenvolvendo trabalhos teóricos e empíricos voltados aos fenômenos sociais, formativos e educacionais à luz desse aporte teórico. Atualmente, a representatividade da Teoria Crítica de Sociedade está nos seguintes grupos de pesquisadores: "Grupo de Pesquisa Teoria Crítica e Educação", criado em 1991, com representantes da Universidade Federal de São Carlos e da Universidade Estadual Paulista - Campus de Araraquara; o "Grupo de Pesquisa Teoria Crítica, Formação e Cultura", com participantes da Universidade de São Paulo e da Pontifícia Universidade Católica de São Paulo; o "Grupo de Pesquisa Nexos: Teoria Crítica e Pesquisa Interdisciplinar Nordeste", formado por pesquisadores de várias instituições de ensino superior. Há inúmeros pesquisadores na Alemanha e em outros países da Europa e de outros continentes que continuam a tradição dos primeiros pesquisadores da Escola de Frankfurt.

Nesse sentido, dialogando com as discussões desses renomados pesquisadores, apresentamos nesse Dossiê uma discussão efervescente e munida de temáticas contemporâneas que tratam do olhar crítico para a sociedade, educação e formação humana, a fim de retomar as contribuições e atualidade do pensamento dialético dos teóricos da Escola de Frankfurt em relação ao fenômeno da indústria cultural e da subsequente transformação da educação em semiformação, ou seja, a expansão do processo de racionalização instrumental do pensamento ocidental quando a cultura aproxima-se dos interesses do mercado e das condições subjetivas que possibilitaram a efetivação e consolidação da semiformação, desarticulando a efetivação do caráter emancipatório da formação.

Há, desse modo, a necessidade pelo processo de educação, de "contrapor-se a tal ausência de consciência", provocada pela indústria em que a cultura se converte unicamente em valor de mercadoria. Adorno (1995) nos alerta que, nos dias de hoje, essa reconciliação entre o indivíduo e a sociedade é forçada, principalmente se determinada pelas relações sociais que exigem a universalização da semiformação e, por que não dizer, da nossa educação danificada. Assim, o pensamento de Adorno renasce quando posto à prova e, portanto, sempre clássico.

O Dossiê está organizado de maneira a acompanhar o movimento do pensamento dos autores da teoria crítica acerca da temática central e, a partir disso, construir um percurso próprio para compreender a formação pedagógica docente neste contexto social vigente, com vista à superação do processo semiformativo pelo processo da emancipação humana. Nesse sentido, os artigos desta coletânea têm o compromisso de pensar criticamente e contribuir para refletir sobre o cenário da educação na atualidade, ao retomar a formação cultural (Bildung), os processos da semiformação (Halbildung) e a indústria cultural. A educação, nesse aspecto, imersa no empobrecimento formativo, influenciada pela indústria cultural, converte-se em determinação social, afetando todos os setores, inclusive o campo formativo e de atuação docente nessa terra 
comum. Assim, a coletânea de discussões objetiva identificar e problematizar a temática envolvente - indústria cultural e o processo da semiformação -, argumento este construído por Adorno sobre uma crise cultural e formativa que afeta o viver do homem em sociedade e sua relação com os bens culturais.

A estrutura didática do Dossiê se pauta incialmente com as discussões acerca da indústria cultural e seus desdobramentos e, sequencialmente, direciona-nos para pensar os efeitos desse novo tempo social e mercadológico, principalmente, com a semiformação e as crises formativas resultantes da cultura vigente.

O florescimento da Teoria Crítica da Sociedade em nossa realidade nos traz indagações que precisam ser refletidas, a fim de potencializar uma análise mais crítica e consistente dos acontecimentos socioculturais, históricos, políticos e, principalmente, formativos. Cabe ressaltar que, urdidos pelos fundamentos da Teoria Crítica da Sociedade, os pensadores frankfurtianos (Adorno, Horkheimer, Marcuse e outros) podem contribuir efetivamente no processo de compreensão do mundo e em favor da humanidade, principalmente quando ajuda "os homens a tirar o véu de maia da realidade sociocultural e política para deixar entrever os artefatos de manipulação ideológica que se escondem sob a aparência do real", uma vez que "trabalham enfaticamente para mostrar os elementos contraditórios, superficiais e aniquiladores tanto da racionalidade quanto da criatividade" (PUCCI; SILVA, 2015, p. 23).

Apresentado pela Revista Ibero-Americana de Estudos em Educação (RIAEE), este dossiê contempla 10 artigos, no formato de ensaio teórico, revisão bibliográfica, análise documental e relatos de pesquisas, de autoria de pesquisadores vinculados a instituições de ensino superior nacionais das diferentes regiões do Brasil: Universidade Estadual de Londrina (UEL); Pontifícia Universidade Católica de São Paulo (PUC); Universidade Estadual de Maringá (UEM); Universidade Estadual Paulista Júlio de Mesquita Filho (UNESP/SP); Universidade de São Francisco (USF); Universidade Estadual do Paraná (UNESPAR); Universidade Federal da Grande Dourados (UFGD/MS); Universidade Estadual de Mato Grosso do Sul (UEMS); Unidade de Dourados; Faculdade Católica Paulista (FACAP); Universidade de São Paulo (USP).

Assim, a discussão inicial sobre a "Indústria cultural e semiformação: democracia e educação sob ataque nos países ibero-americanos à luz da teoria crítica" de autorias de Marta Regina Furlan de Oliveira; Maria Terezinha Bellanda Galuch; Carlos Antônio Giovinazzo Junior analisa o impacto da indústria cultural e da semiformação no continente americano, destacando em como a mercantilização do mercado e da cultura interferiu no desenvolvimento da consciência crítica, tornando-se a forma dominante da consciência contemporânea. Nesse prisma, o ensaio objetiva ampliar o horizonte da reflexão acerca da indústria cultural e da formação danificada, em 
um contexto cuja indústria cultural adquiriu grau elevado de sofisticação e de penetração, inclusive, nos recônditos espaços do Brasil e dos demais países ibero-americanos. Assim, a cultura massificada dá unidade à forma de pensar, de agir, de valorar, enfim, integra a todos por meio do consumo de bens materiais e imateriais.

O texto sobre "Indústria cultural, currículo e formação de professores: a dimensão ética como articuladora no processo pedagógico" de Sandra Regina Mantovani Leite; Alonso Bezerra de Carvalho traz para o debate a ética e os processos pedagógicos como contraponto emancipatório e indispensável para se pensar nos efeitos da indústria cultural na política de elaboração dos currículos e na consequente formação de professores reflexo de um sistema coercitivo. Diante disso, o texto objetiva discutir acerca da dimensão ética presente como articuladora no processo pedagógico docente, com vistas a valorização do ser humano e de todas as suas manifestações.

Desse modo, refletir criticamente sobre a educação e o trabalho docente à luz dos conceitos de semiformação e indústria cultural sob a perspectiva teórico-metodológica de Adorno e Horkheimer, e das possibilidades de resistência à barbárie, que impede a concretização do projeto emancipatório e de esclarecimento do homem e como processo de tomada de consciência e autocrítica é a preocupação dos autores Flávia Regina Schimanski dos Santos, Fernanda Neri de Oliveira e Karina Toledo Araújo com o texto "Indústria cultural e a dialética do esclarecimento: implicações para o trabalho docente na educação física escolar", a fim de pensar em um trabalho docente que contribua para a ruptura do ensino fragmentado e alienado em direção ao esclarecimento e emancipação.

Essa discussão acerca do ensino fragmentado e desconectado da experiência do pensar crítico torna-se um ponto a ser melhor ressignificado, principalmente ao atrelarmos as discussões relacionadas às políticas de avaliação, em especial o Exame Nacional do Ensino Médio (Enem), pela evidente crise no universo da leitura com suas fragilidades, que por sua vez impede o estudante no processo de aquisição de competências e habilidades significativas para o processo de ensino e aprendizagem.

Amparados pelo pensamento de Adorno e Horkheimer e lançando um olhar crítico para a educação na contemporaneidade, que sob os auspícios de uma formação crítica do sujeito sucumbe de forma passiva aos ditames da indústria cultural, Nilo Agostini e Luzia Batista de Oliveira Silva, no artigo "Educação e formação crítica na atualidade", delineiam o panorama da educação na atualidade, de acordo com a Pedagogia Filosófica de Paulo Freire e dos autores da Teoria Crítica da Sociedade, especialmente Walter Benjamin e Theodor Adorno.

“Ainda a semiformação: contribuições de Adorno e Horkheimer em tempos de cibercultura", com as autoras Adriana Regina de Jesus; Daniella Caroline Rodrigues Ribeiro 
Ferreira; Diene Eire de Mello destaca as implicações decorrentes das novas tecnologias no processo formativo, focando no risco de se reduzir a educação a uma racionalidade técnica e ao modo de produção do capitalismo globalizado em tempos de cibercultura.

Nesse sentido, cabe pensar no processo de formação de professores nesse cenário atual, uma vez que as autoras Andréia da Cunha Malheiros Santana; Mariana Civalsci Cardoso; Taila Angélica Aparecida da Silva, no texto "A formação de professores e a teoria crítica: entre o mercado e a emancipação humana", resgatam a necessidade de se pensar a formação docente para a superação de um modelo de formação pautado na racionalidade técnica e estruturado para a lógica mercadológica, contrapondo uma perspectiva de formação que valorize a emancipação e autonomia do ser humano; contribuindo efetivamente para a formação do profissional, articulando teoria e proporcionando a difusão dos saberes historicamente produzidos.

Ainda, dialogando dentro da problemática de formação de professores, enfocando o contexto brasileiro, o artigo "A expansão dos sistemas avaliativos e a teoria crítica: um diálogo (im) pertinente", de Andréia da Cunha Malheiros Santana, Andréia Nunes Militão; Fábio Perboni reflete sobre o modelo avaliativo proposto pelo Estado e como este tem se apresentado como sinônimo de qualidade para a educação no contexto capitalista. A avaliação externa expressa um modelo de qualidade calcado em uma lógica gerencial e técnica, o que contraria as bases da teoria crítica.

Ao pedagogizar a teoria crítica, damos ênfase às dimensões da teoria e da prática que se processa historicamente na sala de aula, uma vez que é nesse espaço dialético, repleto de contradições e possibilidades, que o processo formativo instituído ganha conteúdo e forma. Assim, o artigo de Fabiola Colombani; Flávia Cristina Castilho Carácio; Daniela Maria Maia Veríssimo, "A medicalização e sua história: normalização e disciplinamento da infância por meio da escola", traz uma atual e importante discussão que envolve uma nova forma de produção da civilidade, que é a medicalização no contexto educacional. As autoras se preocupam em tratar da temática por meio de sua história, mostrando alguns indícios de seu surgimento, como também descrevem brevemente o aparecimento da instituição escolar, o desejo burguês da moral e da ordem e a influência médica tanto na família quanto na educação, com o recurso das práticas medicalizantes e biologizantes do processo de aprendizagem, maciçamente presentes no cotidiano escolar atual.

Vale considerar que a medicalização, assim como outros artefatos do consumo, são produtos do avanço da ciência e da tecnologia. Avanços esses que não podem ser negados ou ignorados no meio escolar, cabendo a este promover práticas pedagógicas que superem o momento necessário da 
reprodução e avance no sentido de criar condições para que os indivíduos desenvolvam sua capacidade crítica e emancipatória diante das demandas de consumo atuais.

Desse modo, o ensaio "Produções e produtos culturais na sala-de-aula: uma análise crítico-dialógica do Fandom de Harry Potter e da franquia Meu Malvado Favorito", de Luciane de Paula, Ana Beatriz Maia Barissa e Natasha Ribeiro de Oliveira, se propõe a pensar as produções culturais transformadas em produtos de consumo, em sala-de-aula, como estratégias dialógicas de formação crítica. A proposta é refletir sobre a presença dessas produções e produtos a partir de duas obras icônicas da indústria cultural por sua viralidade: Harry Potter e Meu Malvado Favorito - a maior comunidade de fandom do mundo e o sucesso dos minions, especificamente no Brasil.

A "Pedagogia deliberativa, linguagem e poder: emancipação e transformação social na educação pelo viés da teoria crítica" de Michele Salles El Kadri; Andressa Cristina Molinari; Samantha Mancini Ramos, concebendo a linguagem como meio de dominação e de força social que legitima as relações de poder estabelecidas institucionalmente, neste texto objetivaram apresentar a pedagogia deliberativa como uma possibilidade presente para educar para a emancipação, e se opor à semiformação imposta pela indústria cultural em contexto educacional.

A Teoria Crítica da Sociedade é um convite ao rompimento de um pensamento coisificado para se lançar à aventura intelectual do esclarecimento. Nas palavras de Adorno (1972, p.572):

Quanto mais o pensamento sobre o essencial é mutilado pela tecnificação tanto mais se precisa daquilo que se torna vítima deste processo e daquilo para o qual não há necessidade no mercado, mesmo no mercado cultural. Mas, esse interesse é representado pelo intelectual que não se deixa ser intimidado e é independente o suficiente para reconhecer o controle de sua mente em vez de obedecer.

Assim, encerramos esta apresentação esperando que sua leitura possa provocar reflexões que levem à compreensão da profundidade de uma autêntica formação cultural, renovando internamente e estimulando as experiências intelectuais mais elevadas e propulsoras da resistência à barbárie, tão própria de nossa sociedade e educação danificadas.

\section{REFERÊNCIAS}

ADORNO, T. W. Einleitung zum Vortrag Gesellschaft. In: Gesammelte Schriften. Herausgegeben von Rolf Tiedemann. Band 8. Frankfurt a. M., S.569-573, 1972.

ADORNO, T. W. Mínima Moralia: reflexões a partir da vida danificada. Trad. de Luiz Eduardo Bicca. São Paulo: Ática, 1992 
PUCCI, B; SILVA, L. B. O. Relação atual entre Educação e Teoria Crítica da Sociedade no Brasil. In: LASTÓRIA, L. A. C. N (org) et al. Teoria Crítica: escritos sobre educação: contribuições do Brasil e Alemanha. 1 ed. São Paulo: Nankin, 2015, (p. 10-24).

WIGGERSHAUS, R. A Escola de Frankfurt: história, desenvolvimento teórico, significação política. Trad. de Lilyane Deroche-Gurgel e Vera de Azambuja Harvey. Rio de Janeiro: Difel, 2002.

\section{Como referenciar este artigo}

OLIVEIRA, Marta Regina Furlan de; SILVA, Anilde Tombolato Tavares da; BITTENCOURT, Cândida Alayde de Carvalho; PIASSA, Zuleika Aparecida Claro. Indústria Cultural, Educação e Trabalho Docente: da Semiformação à Emancipação Humana. Revista Ibero-Americana de Estudos em Educação, Araraquara, v. 14, n. esp. 4, p. 1876-1882, dez. 2019. E-ISSN: 1982-5587. DOI: https://doi.org/10.21723/riaee.v14iesp.4.12911

Submetido em: 30/06/2019

Aprovado em: 28/08/2019

Publicado em: 01/09/2019 